\title{
TRAVEL BUBBLE: RISK ANXIETY, RISK ATTITUDE AND INTENTION TO TRAVEL DURING COVID-19 OUTBREAK
}

\author{
Juliana Langgat', Marry Tracy Pawan², Noor Fzlinda Fabeil ${ }^{3}$ \& Khairul Hanim Pazim ${ }^{4}$ \\ 1,2,3,4Faculty of Business, Economics and Accountancy, Universiti Malaysia Sabah \\ (juelanggat@ums.edu.my, marrypawan@ums.edu.my, fzlinda@ums.edu.my, k_hanim@ums.edu.my)
}

\begin{abstract}
The COVID-19 pandemic has made the tourism industry in Malaysia decline drastically. The outbreak has continued for almost two years and has decreased local and international tourist arrivals. The decline is because of the Movement Control Order (MCO) execution, and safety precautions were issued when travelling. Nevertheless, the impressive rate of deterioration in pandemic transmission gives a new shade to domestic tourism. The Tourism Ministry has put forward an initiative that can revitalise the economic sector in the country by introducing the travel bubble destinations among Malaysians. With that, the main purpose of this study is to explore the travel bubble risk anxiety, risk attitude, and intention to travel among Malaysian when COVID-19 is still plaguing the nation. A self-administered survey was conducted online using a snowballing technique. The data collected was keyed in and analysed according to the objectives of this study. The main findings of this study highlighted that those respondents would feel anxious and worried about their safety when participating in the travel bubble. Statistical significance also revealed the respondents' intentions to travel during the COVID-19 outbreak. Further discussions of the findings were also highlighted to deliberate the implications of the study.
\end{abstract}

KEYWORDS: COVID-19, Travel Bubble, Risk Anxiety, Risk Attitude, Intention to Travel

\section{PURPOSE AND BACKGROUND}

The world tourism industry has been severely affected since the COVID-19 pandemic (UWTO, 2020). To date, almost all the tourism and hospitality sectors have had a difficult time, including Malaysia. Hence, to revive the countries tourism and hospitality sectors, the Malaysian government started to introduce Travel Bubble destinations after the Movement Control Order (MCO) was lifted, and there was a reduction in daily cases of infection (New Straits Times, 2021). Travel bubbles also known as "Travel Bridges" or "Corona Corridors".

This initiative was first introduced by Estonia, Latvia and Lithuania, where the citizens from these countries were allowed to enter the borders without any quarantine restrictions (Reuters, 2020). Many countries have started to introduce travel bubble destinations to their citizens to stimulate the national economy during the current pandemic situation (Leung, 2020; Locker, 2020).

It can be seen as a recovery plan to revitalise the tourism and hospitality sectors. The World Health Organisation (WHO) has identified some safe countries to start with as travel bubble destinations, for example, Brunei, Singapore and Thailand or ASEAN countries and Asia Pacific countries such as Japan, South Korea, Australia and New Zealand. Indonesia has given Malaysia the green light for a Reciprocal Green Lane/Travel Corridor Arrangement (RGL/TCA) travel bubble between both nations.

This approval could be an opportunity to boost the economies of both nations after a series of lockdowns following the COVID-19 pandemic (MOTAC, 2021). The COVID-19 outbreak has 
psychological and physiological effects on an individual's health and well-being. It will lead to worse outcomes such as anxiety when rumours or fake news spreads in society. Past studies revealed that anxiety is an incurable sickness and will cause a detrimental behaviour (Taylor, 2019). The pandemic has caused chaos in people daily lives and scared them.

It is crucial to understand to what extent the COVID-19 outbreak has affected people's mental health (Ahorsu et al., 2020; Gnoth et al., 2000). Therefore, the main purpose of this study is to explore the travel bubble risk anxiety, risk attitude, and intention to travel among Malaysians.

\section{METHODOLOGY}

A quantitative approach was employed in this study. A survey questionnaire was formulated using the Google Forms software and distributed using to respondents using a "snowballing" technique getting respondents to point out others in their social circle who are also suitable respondents. The survey instruments used in this study were adopted from Luo and Lam (2020) and consist of six sections. The respondents' demographic profiles were placed in the first section of the questionnaire. The respondents' travel preferences were in the second section.

Sections three to six of the questionnaires asked the respondents about their travel behaviour, travel anxiety, risk attitudes and intent to travel within the travel bubbles. These constructs were measured using a five-point Likert scale ranging from $1=$ strongly disagree to $5=$ strongly agree. The gathered data was then analysed using descriptive and ANOVA tests to derive the findings.

\section{FINDINGS}

The findings of this study can be used as extended literature for the tourism and hospitality industries affected by the COVID-19 pandemic. There are seven significant findings revealed by this study about the tourists' behaviours:

1) they have become more careful in choosing their travel bubble destinations,

2) they are anxious when travelling to COVID-19 destinations even when there are fewer cases reported,

3) they have a positive attitude towards friends and family who visited travel bubble destinations,

4) will recommend to their relatives and friends to visit travel bubble destinations,

5) women tend to have travel anxiety;

6) men have an intention to visit travel bubble destinations,

6) individual age 41 years old and above will visit fewer COVID-19 cases, and

7) concern if friends and families following standard operation procedures (SOPs).

The COVID-19 pandemic significantly influences people's psychology and physiology.

\section{CONCLUSION}

In revitalising the national economy, the government must carefully research this travel bubble initiative. Many aspects should be emphasised where the COVID-19 virus has upended human lives for almost two years since 2019. The tourism and hospitality sector were hugely affected, and Malaysia has lost its earnings from this once lucrative source. Therefore, introducing tourists to visit travel bubble destinations is a wise action.

However, proper plans and standard operation procedures (SOPs) must be thoroughly reviewed. All stakeholders must play an important role to ensure this initiative can be implemented and run smoothly. 


\section{CONTRIBUTION/PRACTICAL IMPLICATIONS}

The findings of this study could be used as extended literature for the tourism and hospitality industries affected by the COVID-19 pandemic. Besides that, the findings of this study have also identified the possible ways that the government can introduce a travel bubble to tourists.

\section{REFERENCES}

Ahorsu, D. K. K., Lin, C. Y. Y., Imani, V. V., Saffari, M. M., Griffiths, M. D. D., Pakpour, A. H. (2020). The fear of COVID-19 scale: Development and initial validation. Int. J. Ment. Heal. Addict, 27, 1-9.

Banerjee, D. (2020). The COVID-19 outbreak: Crucial role the psychiatrists can play. Asian J. Psychiatry, $50,102014$.

Wachyuni, S. S. S., Kusumaningrum, D. A. (2020). The effect of COVID-19 pandemic: How are the future tourist behavior? J. Educ. Soc. Behav. Sci., 67-76. 